\title{
SISTEM PENDUKUNG KEPUTUSAN VALIDASI KELUARGA SANGAT MISKIN PADA PROGRAM KELUARGA HARAPAN (PKH) DENGAN METODE FUZZY BERBASIS WEB
}

\author{
Laila Qadriah $^{(1)}$, Sayed Achmady ${ }^{(2)}$ \\ ${ }^{1,2}$ Program Studi Teknik Informatika, Fakultas Teknik \\ Universitas Jabal Ghafur \\ Email : laila_qadriah@unigha.ac.id ${ }^{(1)}$, sayedachmady@unigha.ac.id ${ }^{(2)}$
}

\begin{abstract}
ABSTRAK
Program Keluarga Harapan (PKH) adalah program nasional dalam membantu keluarga sangat miskin (KSM) guna memperoleh layanan gratis pendidikan dan kesehatan. Validasi keluarga sangat miskin yang pengerjaannya masih manual pada Program Keluarga Harapan (PKH) di Kabupaten Pidie dapat membuat keputusan yang salah. Dimana banyak peserta Program Keluarga Harapan (PKH) saat ini tidak sesuai dengan kriteria KSM yang ada. Kriteria KSM yaitu Luas lantai bangunan tempat tinggal, bahan pembuatan lantai, Jenis dinding tempat tinggal, status kepemilikan tempat buang air besar, Penerangan rumah tangga, Sumber air minum, Bahan bakar memasak, banyaknya mengonsumsi daging/susu/ayam dalam seminggu, banyaknya membeli satu stel pakaian baru dalam setahun, kesanggupan makan dalam sehari, kesanggupan membayar pengobatan di puskesmas/poliknik, Sumber penghasilan kepala rumah dengan pendapatan di bawah Rp 600.000 per bulan, Pendidikan tertinggi kepala rumah tangga, Tidak memiliki tabungan/barang yang mudah di jaul dengan nilai minimal Rp 500.000. Dalam sistem pendukung keputusan ini menggunakan pendekatan dengan menggunakan metode Fuzzy Attribut Decision Making (FMADM) guna memperoleh hasil perhitungan sehingga nantinya menghasilkan keterangan kelayakan suatu rumah tangga layak disebut keluarga sangat miskin.
\end{abstract}

Kata Kunci : Sistem Pendukukung Keputusan, KSM, PKH, Metode Fuzzy Multi Attribut Decision Making (FMADM).

\section{Pendahuluan}

Program Keluarga Harapan (PKH) adalah program nasional dalam membantu Keluarga Sangat Miskin (KSM) di Tanah Air guna memperoleh layanan gratis pendidikan dan kesehatan. Tujuan PKH diantaranya adalah memberikan akses pelayanan pendidikan dan kesehatan secara gratis kepada masyarakat yang masuk domain KSM. Program perlindungan sosial (social protection) semacam ini tidak diragukan lagi sangat bermanfaat bagi minimalisasi angka kemiskinan di suatu negara.

Target program keluarga harapan (PKH) adalah keluarga-keluarga sangat miskin (KSM). Saat ini banyak kita lihat dilapangan khususnya di Kabupaten Pidie, peserta Program Keluarga Harapan (PKH) yang dipilih bukanlah keluarga sangat miskin (KSM) yang tepat. Dimana banyak peserta program keluarga harapan (PKH) saat ini tidak sesuai dengan kriteria KSM yang ada seperti (1) Luas lantai bangunan tempat tinggal kurang dari $8 \mathrm{M}$ persegi per orang, (2) Lantai tempat tinggal terbuat dari tanah/bamboo/kayu murahan, (3) Jenis dinding tempat tinggal terbuat dari bamboo /rumbia /kayu berkualitas rendah/tembok tanpa di plester, (4) Tidak memiliki fasilitas buang air besar/bersama-sama dengan rumah tangga lain, (5) Penerangan rumah tangga tidak mengunakan listrik, (6) Sumber air minum berasal dari air sumur/mata air tidak terlindungi/sungai/air hujan, (7) Bahan bakar memasak untuk sehari-hari adalah kayu bakar/arang/minyak tanah, (8) Hanya mengonsumsi daging/susu/ayam satu kali 
dalam seminggu, (9) Hanya membeli satu stel pakaian baru dalam setahun, (10) Hanya sanggup makan sebanyak satu/dua kali dalam sehari, (11) Tidak sanggup membayar pengobatan di puskesmas/poliknik, (12) Sumber penghasilan kepala rumah tangga adalah petani dengan luas lahan 0,5 ha,buruh tani, nelayan, buruh bangunan, buruh perkebunan,atau pekerjaan lainnya dengan pendapatan di bawah Rp 600.000 per bulan, (13) Pendidikan tertinggi kepala rumah tangga tidak sekolah/tidak tamat SD/hanya SD, (14).Tidak memiliki tabungan/barang yang mudah di jaul dengan nilai minimal Rp 500.000, seperti sepeda motor(kredit/non kredit), emas,ternak,kapal motor,atau barang modal lainnya.

Salah satu teknik pengambilan keputusan yang dapat digunakan dalam pengambilan keputusan dalam pemilihan Keluarga Sangat Miskin (KSM) adalah dengan menggunakan metode Fuzzy Attribut Decision Making (FMADM). Sistem pendukung keputusan merupakan sistem yang membantu pengambil keputusan dengan melengkapi mereka dengan informasi dari data yang telah diolah dengan relevan dan diperlukan untuk membuat keputusan tentang suatu masalah dengan lebih cepat dan akurat. Oleh karena itu sudah sepatutnyalah Dinas Sosial Kabupaten Pidie memiliki suatu sistem pendukung keputusan yang dapat membantu dalam proses pemilihan keluarga sangat miskin (KSM) yang tepat serta sesuai dengan kriteria keluarga sangat miskin (KSM).

\section{Landasan Teori}

\section{Sistem Pendukung Keputusan (DSS)}

Hermawan (2005:23): "Sistem mum

Pendukung Keputusan secara udidefinisikan sebagai sebuah sistem yang mampu memberikan kemampuan baik kemampuan pemecahan masalah maupun kemampuan pengkomunikasian untuk masalah semiterstruktur". Secara khusus, Sistem
Pendukung Keputusan didefinisikan sebagai sebuah sistem yang mendukung kerja seorang manajer maupun sekelompok manajer dalam memecahkan masalah semiterstruktur dengan cara memberikan informasi ataupun usulan menuju pada keputusan tertentu.

Keen dan Scoot Morton (2009:11) : "Sistem Pendukung Keputusan merupakan penggabungan sumber-sumber kecerdasan individu dengan kemampuan komponen untuk memperbaiki kualitas keputusan. Sistem Pendukung Keputusan juga merupakan sistem informasi berbasis komputer untuk manajemen pengambilan keputusan yang menangani masalahmasalah semi struktur “

Berdasarkan pengertian di atas dapat dijelaskan bahwa sistem pendukung keputusan bukan merupakan alat pengambilan keputusan, melainkan merupakan sistem yang membantu pengambil keputusan dengan melengkapi mereka dengan informasi dari data yang telah diolah dengan relevan dan diperlukan untuk membuat keputusan tentang suatu masalah dengan lebih cepat dan akurat. Sehingga sistem ini tidak dimaksudkan untuk menggantikan pengambilan keputusan dalam proses pembuatan keputusan.

\section{Metode Fuzzy Multi Attribut Decision Making (FMADM) \\ FMADM (Fuzzy Multi Attribut}

Decision Making) adalah suatu metode yang digunakan untuk mencari alternatif optimal dari sejumlah alternatif dengan kriteria tertentu. Inti dari FMADM adalah menentukan nilai bobot untuk setiap atribut, kemudian dilanjutkan dengan proses perangkingan yang akan menyeleksi alternatif yang sudah diberikan. (Kusumadewi, dkk, 2006).

Metode ini dikembangkan dalam tiga langkah penting penyelesaian, yaitu:

1. Representasi masalah

2. Evaluasi himpunan fuzzy, dan

3. Seleksi alternative yang optimal 
Ada beberapa metode yang dapat digunakan untuk melakukan agregasi terhadap hasil keputusan para pengambil keputusan, antara lain : mean, median, max, min, dan operator campuran. Dari beberapa metode tersebut, metode mean yang paling banyak digunakan. Operator $\oplus$ dan $\bigotimes$ adalah operator yang digunakan untuk penjumlahan dan perkalian fuzzy. Dengan menggunakan operator mean, $\mathrm{F}_{\mathrm{i}}$ dirumuskan sebagai

$$
F_{t}=\left(\frac{1}{k}\right)\left[\left(S_{t 1} \otimes W_{1}\right) \oplus\left(S_{t 2} \otimes W_{2}\right) \oplus \wedge \oplus\left(S_{t k} \otimes W_{k}\right)\right]
$$

Dengan cara mensubstitusikan $S_{\text {it }}$ dan $\mathrm{W}_{\mathrm{t}}$ dengan bilangan fuzzy segitiga, yaitu $\mathrm{S}_{\mathrm{it}}$ $=\left(o_{i t}, p_{i t}, q_{i t}\right)$; dan $\left.W_{i t}=a_{t}, b_{t}, c_{t}\right)$; maka $F_{t}$ dapat didekati sebagai :

$$
F_{i} \cong\left(Y_{i}, Q_{i}, Z_{i}\right)
$$

Dengan:

$$
\begin{aligned}
Y_{i} & =\left(\frac{1}{k}\right) \sum_{t=1}^{k}\left(o_{i t}, a_{i}\right) \\
Q_{i} & =\left(\frac{1}{k}\right) \sum_{t=1}^{k}\left(p_{i t}, b_{i}\right) \\
Z_{\mathrm{i}} & =\left(\frac{1}{k}\right) \sum_{t=1}^{k}\left(q_{i t}, c_{i}\right) \\
\mathrm{i} & =1,2, \ldots \ldots \ldots . ., \mathrm{n}
\end{aligned}
$$

Karena hasil agregasi ini direpresentasikan dengan menggunakan bilangan fuzzy segitiga, maka dibutuhkan metode perangkingan untuk bilangan fuzzy segitiga. Salah satu metode yang dapat digunakan adalah metode nilai total integral. Misalkan F adalah bilangan fuzzy segitiga, $\mathrm{F}=(\mathrm{a}, \mathrm{b}, \mathrm{c})$, maka nilai total integral dapat dirumuskan sebagai berikut :

$$
I_{T}^{\alpha}(F)=\left(\frac{1}{2}\right)(a c+b+(1-\alpha) a)
$$

Untuk mempermudah pemahaman, disini dilakukan pemecahan rumus ke dalam bahasa alami. Dimana:

$\mathrm{S}_{\mathrm{it}}=\left(\mathrm{o}_{\mathrm{it}}, \mathrm{p}_{\mathrm{it}}, \mathrm{q}_{\mathrm{it}}\right)$; dan $\left.\mathrm{W}_{\mathrm{it}}=\mathrm{a}_{\mathrm{t}}, \mathrm{b}_{\mathrm{t}}, \mathrm{c}_{\mathrm{t}}\right)$; menjadi $S_{\text {kriteria }}=\left(Y_{\text {kriteria }}, Q_{\text {kriteriar }}, Z_{\text {kriteria }}\right) ;$ dan
$\mathrm{W}_{\text {sub_kriteria }}=\mathrm{Y}_{\text {sub_kriteria, }}, \mathrm{Q}_{\text {sub_kriteria, }}$, $\mathrm{Z}_{\text {Sub_kriteria). Berdasarkan persamaan yang }}$ ada, maka persamaan yang digunakan untuk proses perhitungan sehingga mendapatkan nilai fuzzy peserta PKH adalah:

Persamaan I :

$$
\begin{aligned}
& Y_{\text {hasil_kriteria }}=Y_{\text {kriteria }} * Y_{\text {sub_kriteria }} \\
& Q_{\text {hasil_kriteria }}=Q_{\text {kriteria }}{ }^{*} Q_{\text {sub_kriteria }} \\
& Z_{\text {hasil_kriteria }}=Z_{\text {kriteria }} * Z_{\text {sub_kriteria }}
\end{aligned}
$$

Persamaan II:

$$
\begin{aligned}
& \mathrm{Y}_{\text {pesertaPKH }}=\left(\mathrm{Y}_{\text {hasil_kriteria1 }}+\right. \\
& \left.\mathrm{Y}_{\text {hasil_kriteria2................. }}+\mathrm{Y}_{\text {hasil_kriteria...N }}\right) / \mathrm{k} \\
& \mathrm{Q}_{\text {pesertaPKH }}=\left(\mathrm{Q}_{\text {hasil_kriterial }}+\right. \\
& \text { Qhasil_kriteria2................ }+Q_{\text {hasil_kriteria.... }} \text { ) / k } \\
& \mathrm{Z}_{\text {pesertaPKH }}=\left(\mathrm{Z}_{\text {hasil_kriterial }}+\right. \\
& \left.Z_{\text {hasil_kriteria2.................. }}+Z_{\text {hasil_kriteria...N }}\right) / \mathrm{k}
\end{aligned}
$$

dimana $\mathrm{k}=$ jumlah kriteria yang dinilai, dan $\mathrm{N}=$ kriteria terakhir.

Persamaan III:

$$
\begin{aligned}
& \mathrm{I}_{\text {pesertaPKH }}=(1 / 2) \quad\left((\alpha) \quad\left(Z_{\text {pesertaPKH }}\right)+\right. \\
& \left.\left(\mathrm{Q}_{\text {pesertaPKH }}\right)+(1-\alpha)\left(\mathrm{Y}_{\text {pesertaPKH }}\right)\right)
\end{aligned}
$$

Nilai $\alpha$ adalah indeks kooptimisan yang merepresentasikan derajat keoptimisan bagi pengambil keputusan (0 sampai 1). Apabila nilai $\alpha$ semakin besar mengindikasikan bahwa derajat keoptimisannya semakin besar.

\section{Program Keluarga Harapan (PKH)}

Program Keluarga Harapan adalah program yang memberikan bantuan tunai kepada Rumah Tangga Miskin (RTSM). Tujuan umum PKH adalah untuk mengurangi angka dan memutus rantai kemiskinan, meningkatkan kualitas sumber daya manusia, serta merubah perilaku RTSM yang relatif kurang mendukung peningkatan kesejahteraan,dan meastikan generasi berikutnya sehat dan menyelesaikan pendidikan dasar (SD dan SMP).

Kriteria Keluarga Sangat Miskin (KSM) atau Rumah Tangga Sangat Miskin (RTSM) untuk menjadi peserta PKH antara lain:

1. Luas lantai bangunan tempat tinggal kurang dari $8 \mathrm{M}$ persegi per orang

2. Lantai tempat tinggal terbuat dari tanah/bamboo/kayu murahan. 
3. Jenis dinding tempat tinggal terbuat dari bamboo/rumbia/ kayu berkualitas rendah/tembok tanpa di plester

4. Tidak memiliki fasilitas buang air besar/bersama-sama dengan rumah tangga lain

5. Penerangan rumah tangga tidak mengunakan listrik.

6. Sumber air minum berasal dari air sumur/mata air tidak terlindungi/sungai/air hujan.

7. Bahan bakar memasak untuk sehari-hari adalah kayu bakar/arang/minyak tanah.

8. Hanya mengonsumsi daging/susu/ayam satu kali dalam seminggu.

9. Hanya membeli satu stel pakaian baru dalam setahun.

10. Hanya sanggup makan sebanyak satu/dua kali dalam sehari.

11. Tidak sanggup membayar pengobatan di puskesmas/poliknik.

12. Sumber penghasilan kepala rumah tangga adalah petani dengan luas lahan 0,5ha, buruh tani, nelayan, buruh bangunan, buruh perkebunan,atau pekerjaan lainnya dengan pendapatan di bawah Rp 600.000 per bulan.

13. Pendidikan tertinggi kepala rumah tangga tidak sekolah/tidak tamat SD/hanya SD.

14. Tidak memiliki tabungan/barang yang mudah dijaul dengan nilai minimal $\mathrm{Rp}$ 500.000, seperti sepeda motor(kredit/nonkredit), emas,ternak,kapal motor, atau barang modal lainnya.

\section{Metode Penelitian}

\section{Tahap-tahap Perancangan Sistem}

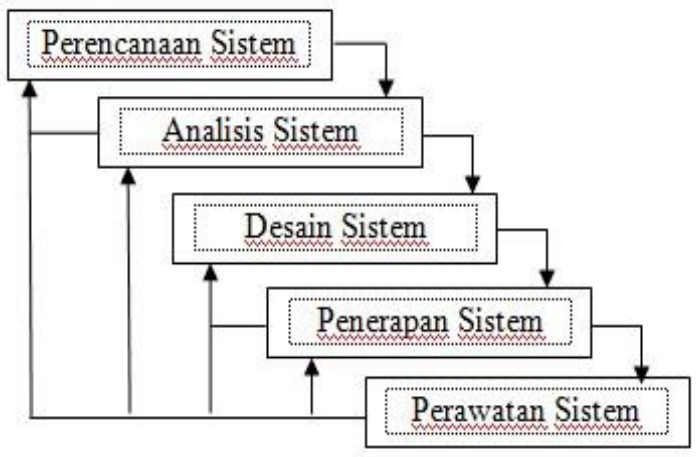

Gambar.1 Tahap-tahap Perancangan Sistem

\section{Hasil Dan Pembahasan \\ Perancangan Sistem}

\section{a. DFD Level 0}

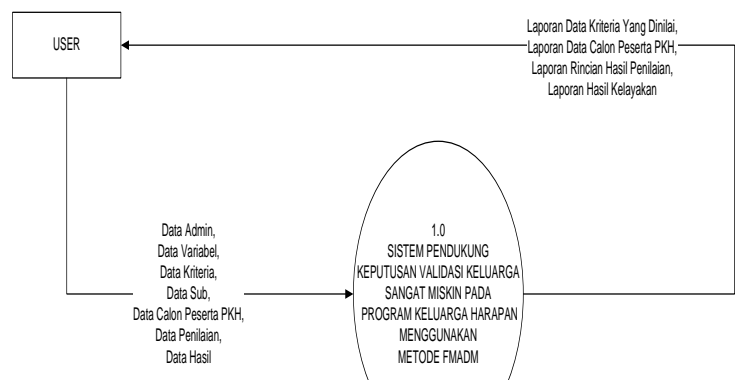

Gambar.2 Data Flow Diagram Level 0

\section{Implementasi Sistem}

1. Halaman Index

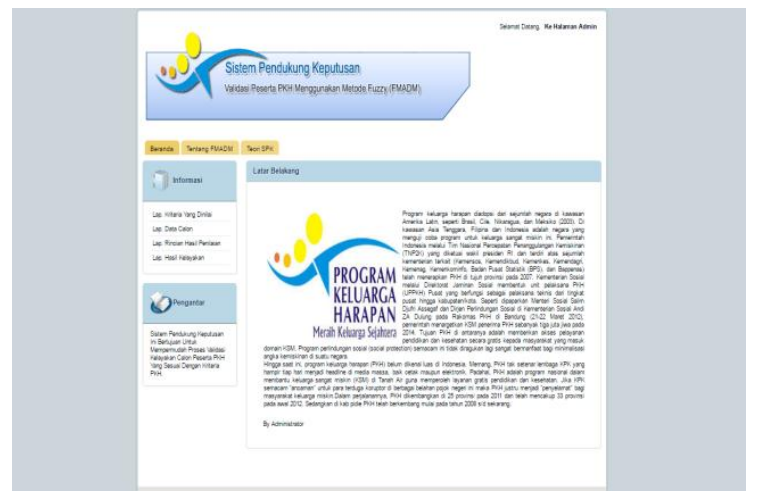

\section{Halaman Login Admin}

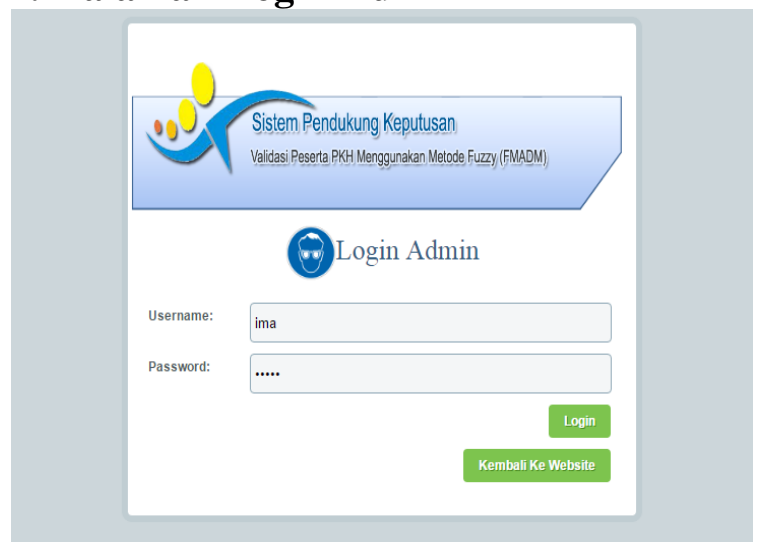

\section{Tampilan Halaman Kelola Data} Variabel

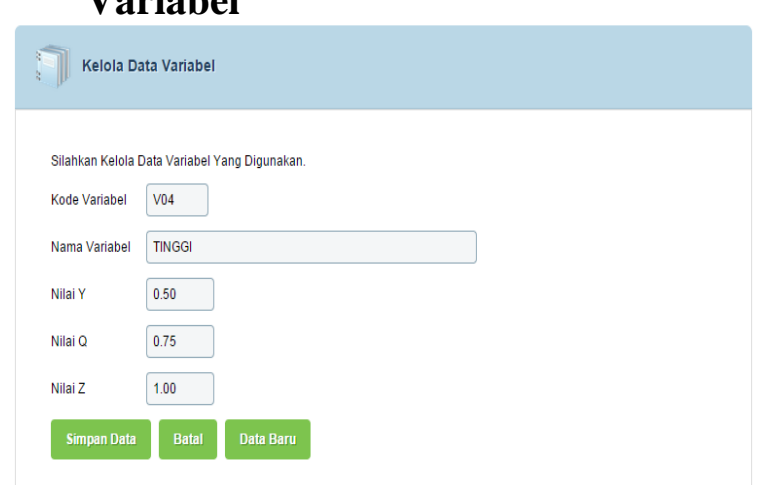




\section{Tampilan Halaman Kelola Data Kriteria}

T.7. Kelola Data Kriteria

Silahkan Kelola Data Kiteria Yang Digunakan.

Kode Kriteria Co

Nama Kriteria LUAS LANTAL BANGUNAN TEMPAT TINGGAL

Variabel SANGAT TINGGI,

\section{SmpanData Batal Data Baru}

\section{Tampilan Halaman Kelola Data Calon} Peserta PKH

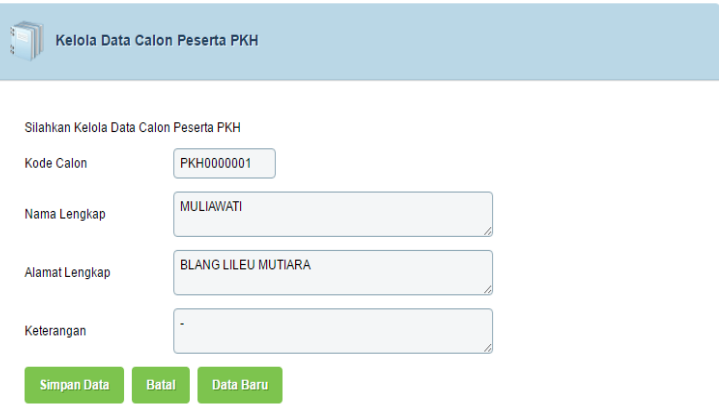

\section{Tampilan Halaman Proses Penilaian} Calon Peserta PKH
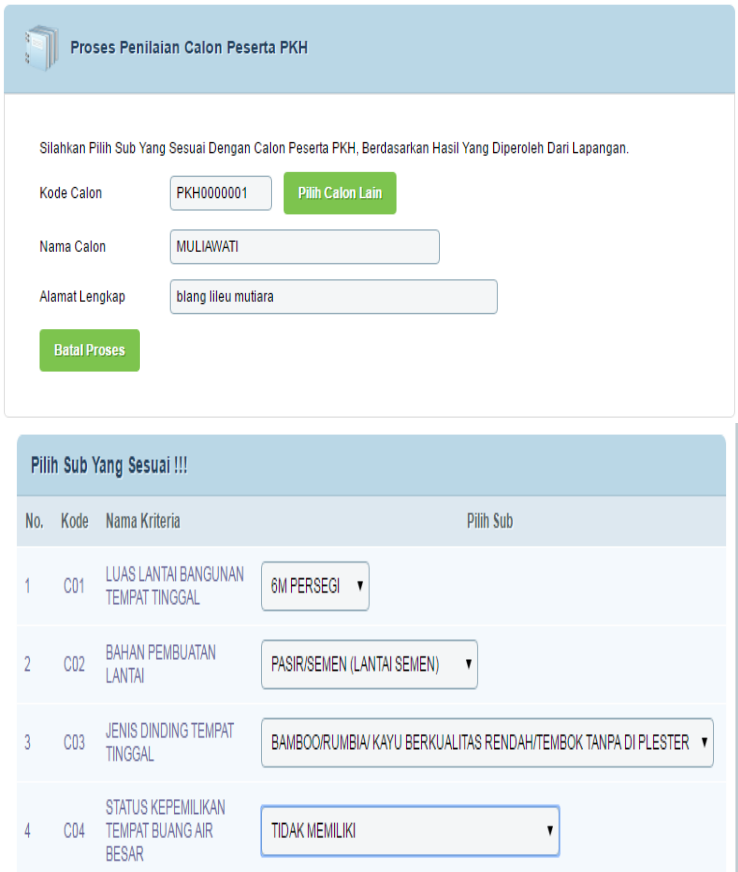

Sampai Dengan

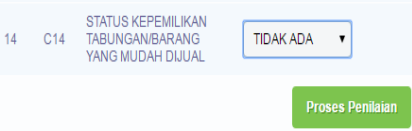

7. Tampilan Halaman Hasil Perhitungan Fuzzy

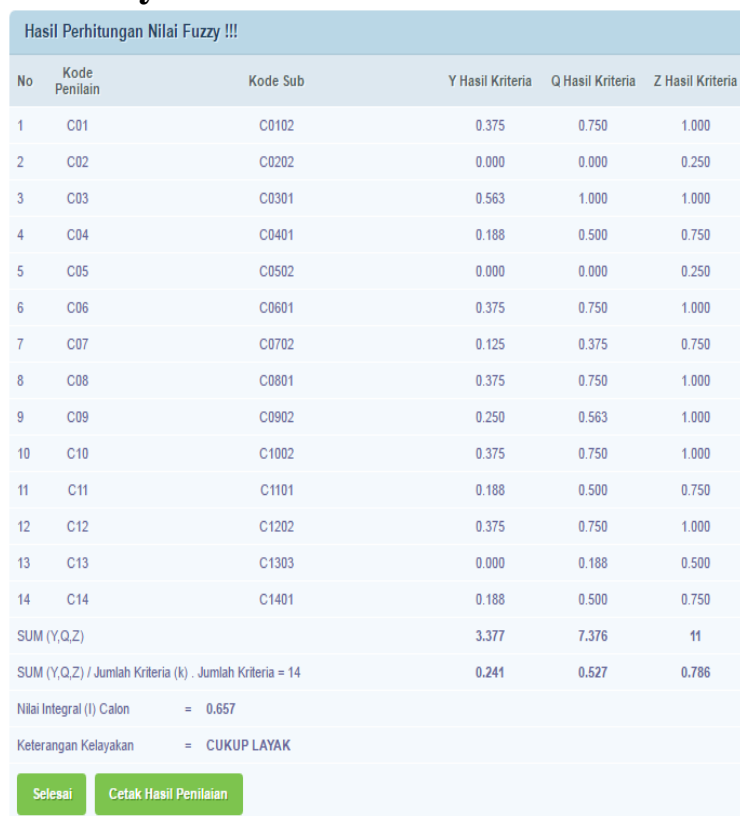

8. Tampilan Laporan Hasil Kalayakan

\begin{tabular}{|c|c|c|c|c|}
\hline \multicolumn{5}{|c|}{ 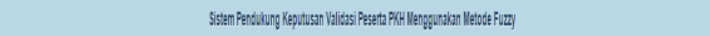 } \\
\hline \multicolumn{5}{|c|}{ Lapora Hasi Kabjyken } \\
\hline & Kole Nencan & Alant & Firitterpl & 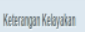 \\
\hline 1 & 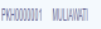 & BRGGLEUNRHA & 067 & OWPPLARE \\
\hline & Promine Zushoh & RARTEAUTHA & 踭 & OWPPLARE \\
\hline
\end{tabular}

\section{Kesimpulan}

Kesimpulan-kesimpulan yang dapat diambil dari hasil penulisan skripsi serta pembuatan sistem pendukung keputusan ini, antara lain:

1. Sistem pendukung keputusan ini dapat mempermudah serta mempercepat proses pengolahan data calon peserta $\mathrm{PKH}$ atau keluarga sangat miskin (KSM) pada Dinas Sosial Tenaga Kerja dan Transmigrasi Kabupaten Pidie.

2. Sistem ini telah mempermudah proses pengambilan keputusan untuk validasi kelayakan calon peserta PKH atau keluarga sangat miskin (KSM).

3. Laporan yang dihasilkan oleh sistem ini dapat dijadikan sebagai acuan dalam pengambilan keputusan yang tepat dalam pemberian program bantuan sosial keluarga harapan.

4. Sistem ini telah mempercepat proses akses informasi mengenai hasil penilaian yang dilakukan oleh Dinas Sosial terkait validasi calon peserta $\mathrm{PKH}$ 
Jurnal Sains Riset (JSR)

$p$-ISSN 2088-0952, $e$-ISSN 2714-531X

\section{Daftar Pustaka}

Ahmad Sgoftan Sauli. 2013. Sistem Pendukung Keputusan Penentuan Penerima Program Keluarga Harapan Pada Kecamatan Dempet Menggunakan Metode Topsis. Universitas Muria : Kudus.

Edwin Satria Permana. 2012. Evaluasi Pelaksanaan Program Keluarga Harapan (PKH) di Kelurahan Saruni Kecamatan Majasari Kabupaten Pandeglang Tahun 2010. Universitas Sultan Ageng Tirtayasa: Serang.

Fitriyani. 2012. Aplikasi AHP Sebagai Model Sistem Pendukung Keputusan Pemilihan Tempat Kuliah di Bangka Belitung. STMIK Arma Luhur Pangkalpinang: Bangka Belitung.

Hadiyanto. 2014. Sistem Pendukung Keputusan Pengangkatan Karyawan Tetap Dengan Metode Fuzzy SAW di CV. Maulaya Tehnik. Universitas Muria: Kudus.

Hermawan. 2005. Sistem Pendukung Keputusan. Wikipedia Berbahasa Indonesia.

JannahNi'matul. 2016. Sistem Pendukung Keputusan penentuan status obesitas menggunakan metode logika fuzzy tsumoko. Universitas Muria: Kudus.

Keen, \& Scot. 2009. Decision Support System and Organizational Perspective. Reading Ma : Addison-Wesley 